\title{
IDENTIFIKASI CITRA DIGITAL KURA-KURA SUMATERA DENGAN PERBANDINGAN EKSTRAKSI FITUR GLCM DAN GLRLM BERBASIS $W E B$
}

\author{
Julia Purnama Sari ${ }^{1}$, Aan Erlansari ${ }^{2}$, Endina Putri Purwandari ${ }^{3}$ \\ 1,2,3 Program Studi Sistem Informasi, Fakultas Teknik, Universitas Bengkulu \\ Jl. WR. Supratman Kandang Limun Bengkulu 38371A, Kota Bengkulu \\ (telp: 0736-341022; fax: 0736-341022)

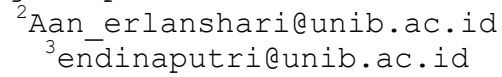

Abstrak: Kura-kura merupakan hewan yang sangat mudah dikenali karena mempunyai bentuk tubuh yang khas. Ciri khas yang dimiliki oleh kura-kura adalah adanya karapaks yang sering disebut dengan cangkang. Dalam mengidentifikasi kura-kura tidak bisa sembarangan, dibutuhkan seorang pakar yang benar-benar paham dengan spesies tersebut. Identifikasi keanekaragaman spesies kura-kura sumatera melalui pengolahan citra digital ini menggunakan metode ekstraksi fitur tekstur berbasis website. Salah satu cara mengidentifikasi jenis kura-kura yaitu dengan menggunakan sistem identifikasi secara otomatis berbasis pemrosesan citra digital. Pada penelitian ini dilakukan perbandingan dua ekstraksi ciri yaitu Gray Level Co-Occurrence Matrix (GLCM) dan Gray Level Run Length Matrix (GLRLM). Ekstraksi ciri GLCM dan GLRLM yang dilakukan pada penelitian ini menggunakan sudut $0^{\circ}, 45^{\circ}, 90^{\circ}, 135^{\circ}$. Hasil Penelitian menunjukkan bahwa hasil akurasi identifikasi dengan menggunakan ekstraksi ciri GLRLM lebih baik dibandingkan GLCM. Hasil Akurasi tertinggi pada GLRLM 79,5\% sementara dengan GLCM menghasilkan akurasi sebesar $75 \%$.

Kata Kunci: Identifikasi, Kura-kura, Karapaks, Gray Level Run length Matrix, Gray Level CoOccurrence Matrix.

\begin{abstract}
Turtles are very easily recognized animals because they have a distinctive body shape. The distinctive feature of turtles is the presence of a carapace which is often called a shell. In identifying turtles, you need an expert who really understands the species. Identification of the diversity of Sumatran turtle species through digital image processing using the texture extraction method, with website-based. One way to identify the type of turtle is using an automatic system based on digital images. In this study, two feature extractions were compared, namely Gray Level Co-Occurrence Matrix (GLCM) and Gray Level Run Length Matrix (GLRLM). The feature extraction of GLCM and GLRLM was carried out in this study using an angle of $0^{\circ}, 45^{\circ}, 90^{\circ}, 135^{\circ}$. The results showed that the results using GLRLM feature extraction were better than GLCM. The highest accuracy results in GLRLM are $79.5 \%$ while GLCM produces an accuracy of $75 \%$.
\end{abstract}

\section{PENDAhULUAN}

Kura-kura merupakan hewan reptil yang sangat mudah dikenali karena mempunyai bentuk tubuh khas. Ciri khas yang dimiliki oleh kura-kura adalah adanya cangkang yang disebut karapas pada bagian dorsal dan plastron pada bagian vetral. Morfologi kepala, tungkai, dan karakter keping perisai karapas serta plastron dapat dijadikan ciri identifikasi jenis pada kura-kura [1].

Penelitian Keanekaragaman Jenis Reptil dan Biologi Cyrtodactylus cf fumosus, di Taman Nasional Bukit Barisan Selatan LampungBengkulu tahun 2006 ini menyatakan bahwa, Indonesia menempati peringkat ketiga sebagai 
Jurnal Pseudocode, Volume VIII Nomor 1, Februari 2021, ISSN 2355-5920, e-ISSN 2655-1845 www.ejournal.unib.ac.id/index.php/pseudocode

negara yang memiliki kekayaan jenis reptil paling tinggi di dunia, lebih dari 600 jenis reptil terdapat di Indonesia [2]. Tingkat keanekaragaman hayati yang tinggi ini menyebabkan Indonesia memiliki endemisitas jenis fauna yang sangat tinggi bahkan untuk beberapa kelompok seperti burung, mamalia dan reptil memiliki endemisitas tertinggi di dunia. Reptil merupakan salah satu fauna yang banyak terdapat di wilayah Bengkulu, salah satunya adalah kura-kura.

Dalam mengidentifikasi kura-kura tidak bisa sembarangan, dibutuhkan seorang pakar yang benar-benar paham dengan spesies tersebut. Di Kota Bengkulu terdapat salah seorang yang ahli di bidang ilmu kura-kura sumatera adalah bapak Dr. Aceng Ruyani, M.S. Beliau adalah salah satu dosen magister Pendidikan Ilmu Pengetahuan Alam di Universitas Bengkulu.

Dengan memanfaatkan teknologi citra digital maka citra cangkang kura-kura bagian atas atau karapaks juga dapat diproses untuk mendapatkan hasil identifikasi jenis kura-kura. Cara ini dapat menjadi salah satu cara untuk menyelesaikan permasalahan seseorang dalam mengidentifikasi jenis kura-kura secara manual. Teknologi citra digital mengidentifikasi jenis kura-kura dapat dilakukan berdasarkan fitur tekstur dari citra cangkang kura-kura.

Identifikasi keanekaragaman spesies kura-kura sumatera melalui pengolahan citra digital ini menggunakan metode ekstraksi fitur warna dan tekstur. Karena setiap karapaks kura-kura memiliki fitur warna yang berbeda, dan fitur tekstur yang berbeda.

Penelitian terkait dengan pengolahan citra pernah dilakukan sebelumnya oleh M.Rodhi Supriyadi [3] yang melakukan penelitian identifikasi jenis kura-kura dengan metode color moment dan Gray Level Co-occurrence Matrix (citra diambil menggunakan smartphone). Penelitian lain menggunakan ekstraksi fitur tekstur menggunakan metode Gray Level Co-occurrence Matrix dan Gray Level Run Length Matrix [4]. Penelitian lain dilakukan oleh Irvie Augustin [5] identifikasi jenis kelamin dengan menggunakan metode Gray Level Co-Occurrence Matrix (GLCM) dan metode Support Vector Machine (SVM). Penelitian lainnya Sella Kusumaningtyas (2016) Identifikasi Kematangan Buah Tomat Berdasarkan Warna Menggunakan Metode Jaringan Syaraf Tiruan (JST) [6]. Pada penelitian yang berjudul Penerapan Metode Ekstraksi dan Klasifikasi Fitur untuk gambar histopatologis menggunakan GLRLM dan LBP menjelaskan perbandingan tingkat efektifitas metode Gray Level Run Length Matrix dengan metode Local Binary Pattern sebagai ekstraksi tekstur. Kedua metode ekstraksi tekstur tersebut mendapat nilai akurasi yang berbeda LBP 89.6\% dan GLRLM 91.7\%. Perbandingan nilai akurasi yang telah didapat maka metode Gray Level Run Length Matrix memiliki keunggulan dibandingkan dengan metode ekstraksi tekstur Local Binary Pattern.

Secara umum kebanyakan orang hanya mengetahui kura-kura tanpa tahu jenisnya. Agar masyarakat dapat membedakan jenis kura-kura dengan tepat, maka perlu adanya pengenalan terhadap kura-kura yaitu dengan cara mengidentifikasi jenis kura-kura yang ada. Dengan memanfaatkan teknologi citra digital maka, citra cangkang kura-kura bagian atas atau karapaks dapat diproses untuk mendapatkan hasil identifikasi jenis kura-kura. Mengidentifikasi jenis kura-kura dengan menggunakan teknologi citra digital dapat dilakukan berdasarkan fitur tekstur dari citra cangkang kura-kura tersebut. Sementara 
Jurnal Pseudocode, Volume VIII Nomor 1, Februari 2021, ISSN 2355-5920, e-ISSN 2655-1845 www.ejournal.unib.ac.id/index.php/pseudocode

itu, hasil identifikasi jenis kura-kura dapat menjadi sebuah informasi bagi para peneliti maupun dapat digunakan sebagai media pembelajaran. Oleh karena itu, diperlukan aplikasi untuk pengidentifikasian kura-kura yang dapat disajikan dalam multimedia interaktif sebagai pembelajaran konservasi kura-kura bagi siswa dan pihak terkait.

\section{LANDASAN TEORI}

\section{A. Citra Kura-Kura Sumatera}

Kura-kura merupakan hewan yang sangat mudah dikenali karena mempunyai bentuk tubuh khas. Morfologi kepala, tungkai, dan karakter keping perisai karapas serta plastron dapat dijadikan penciri identifikasi jenis pada kura-kura. Keseluruhan jenis kura-kura di dunia diperkiraan lebih dari 285 spesies yang terbagi dalam 14 familia. Di Indonesia terdapat sekitar 45 spesies dari 7 familia. Sedangkan di wilayah Kalimantan diperkirakan terdapat 25 spesies dari 6 familia [7]. Kura-kura cocok hidup di daerah Bengkulu karena Bengkulu memiliki lautan, sungai, rawa, hutan bahkan padang rumput, ini merupakan habitat asli kura- kura. Ciri khas yang dimiliki oleh kura-kura adalah adanya cangkang yang disebut Karapaks. Ukuran kura-kura berkisar dari 11-185 cm [2]

Dengan memanfaatkan teknologi citra digital maka, citra cangkang kura-kura bagian atas atau karapaks dapat diproses untuk mendapatkan hasil identifikasi jenis kura-kura. Mengidentifikasi jenis kura-kura dengan menggunakan teknologi citra digital dapat dilakukan berdasarkan fitur tekstur dari citra cangkang kura-kura tersebut. Menentukan karakter fisik suatu jenis melalui pengamatan morfologi untuk dideskripsikan lalu dikelompokkan menjadi hierarki, baik itu secara taksonomik maupun hubungan filogenik. Sementara itu, hasil identifikasi jenis kura-kura dapat menjadi sebuah informasi bagi para peneliti maupun dapat digunakan sebagai media pembelajaran. Selain itu keuntungan yang didapatkan dengan menggunakan citra digital yaitu, seseorang tidak perlu harus menghabiskan banyak uang agar dapat berkonsultasi dengan seorang pakar.

Jenis kura-kura yang ada di Sumatera sebanyak 16 jenis, dan untuk di Bengkulu terdapat 10 jenis kura-kura. Dalam penelitian ini jenis kura-kura yang akan diidentifikasi terdapat 7 jenis kura-kura yang berbeda yaitu kura-kura nanas/ duri/ matahari ((heosemys spinosa), kura- kura garis hitam (cyclemys odhamil), kura-kura patah dada/ batok (coura amboinensis), kura- kura beiyogo/ tempurung datar (notochelys platynota), kura-kura baning cokelat (manouria emys), kura-kura pipi putih (siebenrockiella crassiocollis), dan kura-kura biuku/ gading (ortilia borneensis).

\section{B. Gray Level Run Length Matrix}

Gray Level Run-Length Matrix (GLRLM) adalah matriks tempat fitur tekstur dapat diekstraksi untuk analisis tekstur. Tekstur dipahami sebagai pola piksel intensitas abu-abu dalam arah tertentu dari piksel referensi. Panjang run adalah jumlah piksel yang berdekatan yang memiliki intensitas abu-abu yang sama dalam arah tertentu [8]. Pada metode run-length orientasi dibentuk dalam empat arah sudut dengan interval sudut, yaitu $0^{\circ}, 45^{\circ}, 90^{\circ}$, dan $135^{\circ}$.

Tekstur dipahami sebagai pola piksel intensitas abu-abu dalam arah tertentu dari piksel referensi. Grey-Level Run-Length Matrix (GRLM) adalah matriks dari mana fitur tekstur dapat diekstraksi untuk analisis tekstur. Ini adalah cara menelusuri gambar, selalu melintasi arah tertentu, untuk piksel yang memiliki nilai tingkat abu-abu yang sama. 
Jurnal Pseudocode, Volume VIII Nomor 1, Februari 2021, ISSN 2355-5920, e-ISSN 2655-1845 www.ejournal.unib.ac.id/index.php/pseudocode

Panjang run adalah jumlah piksel yang berdekatan yang memiliki intensitas abu-abu yang sama dalam arah tertentu [9].

Metode grey level run length merupakan salah satu cara untuk mengekstraksi fitur statistik tingkat tinggi [8]. GLRLM adalah kumpulan piksel berkelanjutan yang memiliki tingkat abu-abu yang sama. Run adalah jumlah tingkat abu-abu yang berdekatan dalam arah tertentu. Ini dihitung dengan menghitung berapa kali proses yang sesuai terjadi pada gambar.

Pada penelitian ini, akan digunakan lima ciri tekstur dasar Metode Gray Level Run Length Matrix, yaitu Short Run Emphasis (SRE), Long Run Emphasis (LRE), Grey Level non-Uniformity (GLU), Run Length nonUniformity (RLU), Run Percentage (RPC) dengan rumus sebagai berikut [2].

\section{Short Run Emphasis (SRE)}

Nilai fitur ini sangat bergantung pada banyaknya short run dan diharapkan bernilai kecil pada tekstur kasar dan bernilai besar pada tekstur yang halus.

$\boldsymbol{S} \boldsymbol{R} \boldsymbol{E}=\sum_{i=1}^{M} \sum_{j=1}^{N} \frac{p(i, j) / s}{j 2}$

\section{Long Run Emphasis (LRE)}

Nilai fitur ini sangat bergantung pada banyaknya long run dan diharapkan bernilai besar pada tekstur yang kasar dan bernilai kecil pada tekstur yang halus.

$\boldsymbol{L} \boldsymbol{R} \boldsymbol{E}=\sum_{i=1}^{M} \sum_{j=1}^{N} \frac{j 2 p(i, j)}{s}$

3. Grey Level non-Uniformity (GLU)

Nilai fitur ini mengukur persamaan nilai derajat keabuan diseluruh citra dan diharapkan bernilai kecil jika nilai derajat keabuan serupa diseluruh citra.

$\boldsymbol{G} \boldsymbol{L} \boldsymbol{U}=\sum_{i=1}^{M}\left(\sum_{J=1}^{N} p(i, j)\right) 2 / s$
4. Run Length non-Uniformity (RLU)

Nilai fitur ini mengukur persamaan panjangnya run diseluruh citra dan diharapkan bernilai kecil jika panjangnya run serupa diseluruh citra.

$\mathbf{R L U}=\sum_{j=1}^{N}\left(\sum_{I=1}^{M} p(i, j)\right) 2 / s$

5. Run Percentage (RPC)

Nilai fitur ini mengukur keserbesamaan dan distribusi run dari sebuah citra.

$\left.\mathbf{R P C}=\sum_{i=1}^{M} \sum_{J=1}^{N} p(i, j)\right) / n$

\section{GRAY LEVEL CO-OCCURRENCE MATRIX (GLCM)} Metode GLCM (grey-level co-occurrence matrix) adalah salah satu cara mengekstrak fitur tekstur statistik orde -kedua. Selain itu menurut Mryka Hall-Bayer, GLCM merupakan tabulasi mengenai frekuensi atau seberapa seringnya kombinasi nilai dengan demikian, dapat disimpulkan bahwa metode Grey Level Cooccurrence Matrix merupakan salah satu cara mengekstraksi fitur tekstur untuk mengetahui seberapa seringnya kombinasi nilai kecerahan pixel dengan posisi berbeda.

Dalam analisis tekstur statistik, fitur tekstur dihitung berdasarkan distribusi statistik intensitas piksel pada posisi tertentu relatif terhadap yang lain dalam matriks piksel yang mewakili gambar. Bergantung pada jumlah piksel atau titik di setiap kombinasi, kami memiliki statistik urutan pertama, statistik urutan kedua, atau statistik urutan lebih tinggi [8].

Terdapat 4 ciri tekstur GLCM yaitu Energy, Contrast, Correlation, dan Homogenity. Berikut ini merupakan parameter yang relevan beserta persamaan [4]: 
Jurnal Pseudocode, Volume VIII Nomor 1, Februari 2021, ISSN 2355-5920, e-ISSN 2655-1845 www.ejournal.unib.ac.id/index.php/pseudocode

1) Energy

Energy adalah pengukuran tekstur dari gambar gray scale yang merepresentasikan perubahan homogeneity, merefleksikan keseragaman berat dan tekstur distribusi gambar grayscale. Energy dihitung dengan menggunakan persamaan (2.1).

$E=\sum_{x} \sum_{y} P(x, y)^{2}$

\section{2) Contrast}

Contrast adalah diagonal utama yang mengukur nilai matriks yang terdistribusi, merefleksikan kejelasan gambar dan tekstur kedalaman bayangan. Contrast dihitung dengan menggunakan persamaan (2.2).

$I=\sum \sum(x-y)^{2} P(x, y)$

\section{3) Correlation}

Correlation mengukur keterhubungan linear tingkat keabuan satu piksel relatif terhadap piksel lannya pada posisi tertentu. Correlation dihitung dengan menggunakan persamaan (2.3).

$C=\frac{1}{\sigma^{2}}\left(\left(\sum_{x} \Sigma_{y}(x * y) P(x, y)\right)-\mu^{2}\right)$

4) Homogenity

Homogeneity mengukur nilai perubahan lokal pada tekstur gambar. Homogenity dihitung dengan menggunakan persamaan (2.4).

$H=\sum_{x} \sum_{y} \frac{1}{1+(x-y)^{2}} P(x, y)$

Keterangan:

$$
\begin{aligned}
& E \quad=\text { Energy } \\
& I \quad=\text { Contrast } \\
& C \quad=\text { Correlation } \\
& \sigma \quad=\text { Variansi } \\
& \mu \quad=\text { Rata-rata } \\
& H \quad=\text { Homogeneity } \\
& P(x, y)=\text { Nilai pasangan piksel } x \text { dan } y
\end{aligned}
$$

\section{METODE PENELITIAN}

\section{A. Alat dan Bahan}

Berikut alat dan bahan yang dibutuhkan dalam pengembangan sistem ini, yaitu:

1. Input dari sistem adalah citra cangkang kura-kura dan output-nya adalah informasi klasifikasi jenis kura-kura yang ada pada citra tersebut.

2. Citra cangkang kura-kura bagian atas atau karapaks yang akan diidentifikasi ini terdiri dari dari tujuh jenis kura-kura yang berbeda yaitu kura-kura nanas/ duri/ matahari (heosemys spinosa), kura-kura garis hitam (cyclemys odhamil), kura-kura patah dada/ batok (coura amboinensis), kura-kura beiyogo/ tempurung datar (notochelys platynota), kura-kura baning cokelat (manouria emys), kura-kura pipi putih (siebenrockiella crassiocollis), dan kura-kura biuku/ gading (ortilia borneensis). Ketujuh jenis kura-kura tersebut ditangkar oleh pihak Sumber Belajar Ilmu Hayati (SBIH) Ruyani.

3. Khusus untuk kura-kura nanas/ duri/ matahari (heosemys spinosa) akan dibedakan menjadi dua yaitu kura-kura muda dan kura-kura dewasa.

4. Citra yang digunakan pada penelitian ini adalah citra berwarna berukuran 3024 x 4032 dengan format JPEG yang diambil menggunakan kamera Smartphone Samsung S7 Edge 12 Megapixel.

5. Jumlah citra yang digunakan sebanyak 100 citra terdiri dari 56 citra latih karapaks kura- kura Bengkulu, 44 citra uji karapaks kura-kura yang diambil menggunakan smartphone. 
Jurnal Pseudocode, Volume VIII Nomor 1, Februari 2021, ISSN 2355-5920, e-ISSN 2655-1845 www.ejournal.unib.ac.id/index.php/pseudocode

6. Perangkat lunak (softiware), antara lain: Sistem Operasi Windows 10, Microsoft Office 2013, Microsoft Office Visio 2013, Balsamiq Mockups 3, Python 3.8.2, Visual Studio Code, Google Chroome

7. Perangkat Keras (hardware), antara lain: Laptop ASUS, Processor Intel Core i5, RAM 4 GB, Harddisk 64 GB, Mouse.

\section{B. Pelaksanaan Penelitian}

Penelitian mengenai aplikasi identifikasi citra ini termasuk dalam penelitian terapan (applied research). Pada penelitian ini dibuat sebuah aplikasi yang mampu mengidentifikasi cangkang kura-kura yang memiliki kemiripan paling dekat dengan citra masukan cangkang kura-kura bagian atas dengan menerapkan Jaringan Syaraf Tiruan, Gray Level Co-occurrence Matrix dan Hue Intensity Saturation. Penelitian ini juga dilakukan untuk mengetahui tingkat akurasi penggunaan metode GLCM dan GLRLM dalam ekstraksi fitur citra cangkang kura-kura.

Metode pengumpulan data dilakukan dengan cara menemui pakar di bidang ilmu kura- kura sumatra, yaitu bapak Dr. Aceng Ruyani, M.S beliau adalah salah satu dosen magister Pendidikan Ilmu Pengetahuan Alam di Universitas Bengkulu. Wawancara yang dilakukan berkaitan erat dengan informasi detail tentang data kura-kura yang akan menunjang penelitian yang dilakukan.

\section{HASIL DAN PEMBAHASAN}

\section{A. Analisis Masalah}

Cara kerja aplikasi identifikasi citra pada umumnya menggunakan nilai ekstraksi fitur tekstur dan warna dari masing-masing citra, dikarenakan banyaknya jenis kura-kura yang ada membuat sulitnya dalam mengidentifikasi jenis kura-kura. Adapun cara untuk menyelesaikan masalah tersebut adalah dengan menggunakan Gray Level Cooccurrence Matrix dan Hue Saturation Intensity sebagai ekstraksi fitur tekstur dan warna yang telah terbukti efisien dalam mengekstraksi tekstur citra.

\section{B. Analisis Sistem}

Sebelum membuat sebuah sistem atau aplikasi maka terlebih dahulu harus melakukan analisis sistem atau aplikasi. Analisis sistem ini meliputi analisis fungsional, analisis pengguna, dan analisis alur kerja system.

\section{Analisis fungsional}

Analisis fungsional adalah analisis yang berisiskan proses-proses yang dapat dilakukan oleh aplikasi yang nantinya akan dibangun. Berikut adalah proses-proses yang dapat dilakukan oleh aplikasi.

a. Aplikasi dapat melakukan identifikasi citra uji yang memiliki kemiripan dengan citra latih menggunakan metode GLCM dan GLRLM

b. Aplikasi dapat menampilkan informasi nilai ekstraksi ciri dari citra uji dan informasi hasil identifikasi citra.

c. Aplikasi dapat memberikan informasi mengenai ketujuh jenis kura-kura Bengkulu.

\section{Analisis antarmuka Pengguna}

Analisis antarmuka dibuat berdasarkan alur penggunaan antarmuka mulai dari pengguna menginputkan citra uji sampai dengan sistem menghasilkan keluaran yaitu citra latih yang memiliki kemiripan dengan citra uji. Pada sistem ini, baik input maupun output merupakan citra 
Jurnal Pseudocode, Volume VIII Nomor 1, Februari 2021, ISSN 2355-5920, e-ISSN 2655-1845 www.ejournal.unib.ac.id/index.php/pseudocode

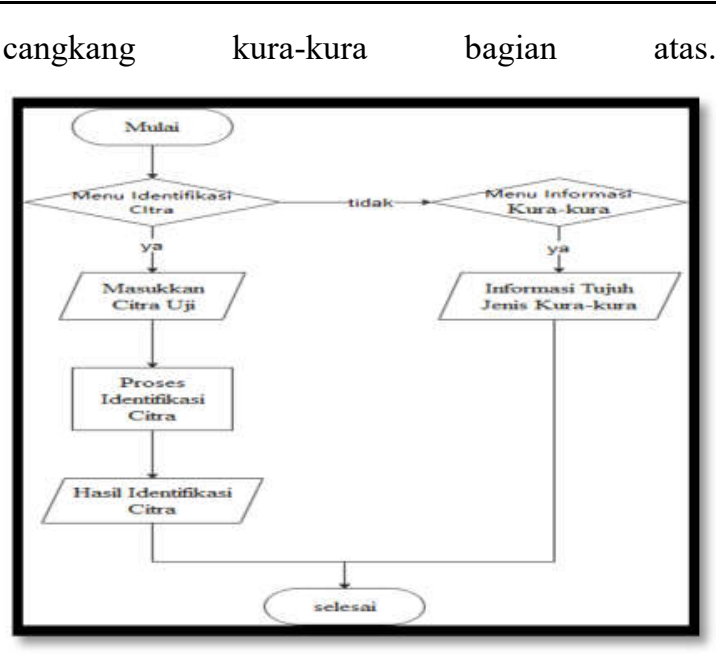

Gambar 1. Diagram Antarmuka Pengguna

\section{Analisis Alur Kerja Sistem}

Setelah menganalisis antarmuka pengguna, perlu dilakukan pula analisis terhadap alur kerja sistem. Analisis alur kerja sistem penting untuk dilakukan karena analisis ini bertujuan untuk menjelaskan alur kerja dari sebuah sistem secara berurut yang dimulai dari user memasukkan sebuah masukan sampai dengan user menerima sebuah keluaran dari sistem yang keluaran tersebut telah diproses terlebih dahulu oleh sistem. Alur dari aplikasi ini memiliki 7 tahap yaitu komponen diagram alur yang dimulai dari komponen mulai hingga komponen selesai.

1. Pengguna memulai sistem selanjutnya, pengguna memasukkan citra cangkang kurakura bagian atas dengan format *.jpg ke dalam sistem.

2. Setelah itu, masuk ketahap preprocessing pada tahap ini citra diubah resizenya menjadi 256x256 proses ini dilakukan untuk mengambil background. Selain itu proses ini juga dapat mengubah ukuran citra menjadi lebih kecil sehingga mempercepat proses komputasi. Sehingga citra cangkang kura-kura dapat terpisah dengan background-nya.
Berikut contoh gambar dengan K-means Clustering:

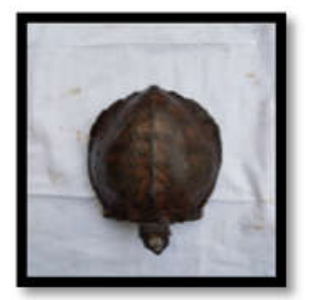

(a)

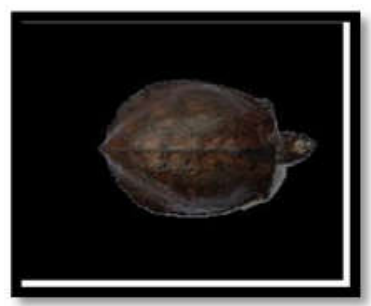

(b)
Gambar 2. Proses pemisahan background

3. Setelah preprocessing segmentasi dengan kemudian sistem akan melakukan ekstraksi fitur tekstur citra dengan menggunakan $G L C M$ dan GLRLM agar diperoleh citra hasil ekstraksi tekstur.

\section{Hasil Pengujian Identifikasi}

Identifikasi citra dalam aplikasi ini menggunakan metode GLCM dan GLRLM digunakan untuk mengidentifikasi dari citra uji dan citra latih yang ada pada memori komputer, kemudian nilai ekstraksi ciri tersebut akan dicocokan kemiripannya.

Perhitungan akurasi dari identifikasi citra cangkang kura-kura bagian atas dengan menggunakan smartphone. Citra yang di uji adalah 44 citra cangkang kura-kura bagian atas. Tabel 1 merupakan tabel dari beberapa hasil pengujian citra yang diambil menggunakan smartphone.

Tabel 1.Pengujian Citra Cangkang Kura-kura Bagian Atas Menggunakan Smartphone

\begin{tabular}{|l|l|l|l|l|}
\hline & \multicolumn{2}{|c|}{ GLCM } & \multicolumn{2}{c|}{ GLRLM } \\
\hline \multicolumn{1}{|c|}{ Citra } & \multicolumn{1}{|c|}{ Hasil } & Keterangan & \multicolumn{1}{c|}{ Hasil } & Keterangan \\
identifikasi & & identifikasi & \\
\hline Jenis : & Kura-kura & Berhasil & Kura-kura & Berhasil \\
Kura & Nanas & & Nanas & \\
Nanas & Dewasa & & Dewasa & \\
Dewasa & (Heosemys & & $\begin{array}{l}\text { (Heosemys } \\
\text { spinosa) }\end{array}$ & \\
& spinosa) & & Kura-kura & Berhasil \\
\hline 2017122 & Kura-kura & Berhasil & Nanas & \\
8_17280 & Nanas & & Dewasa & \\
3.jpg & Dewasa & & (Heosemys & \\
Jenis : & (Heosemys & & spinosa) & \\
Kura & spinosa) & & & \\
Nanas & & & & \\
Dewasa & & & & \\
\hline
\end{tabular}


Jurnal Pseudocode, Volume VIII Nomor 1, Februari 2021, ISSN 2355-5920, e-ISSN 2655-1845 www.ejournal.unib.ac.id/index.php/pseudocode

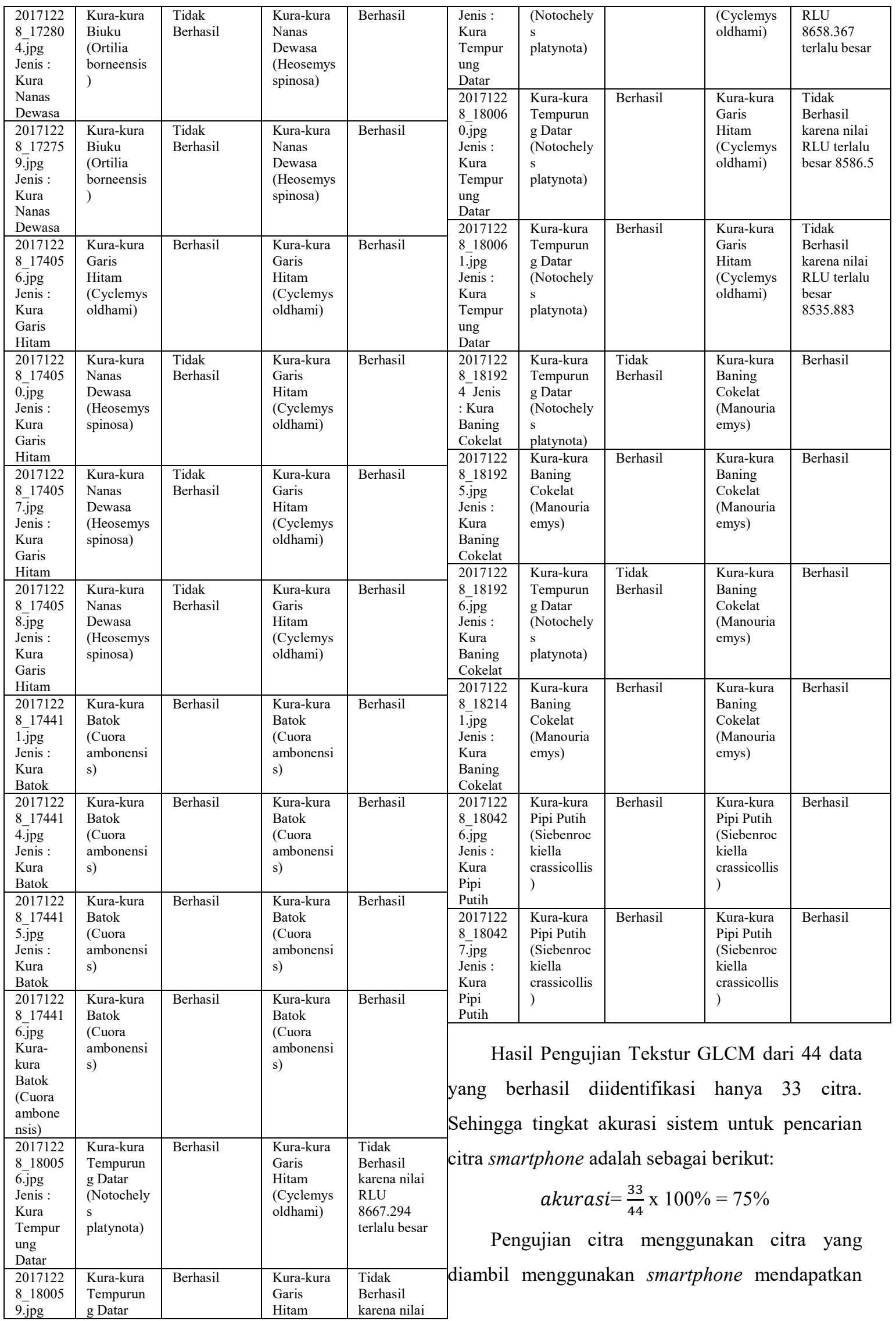


Jurnal Pseudocode, Volume VIII Nomor 1, Februari 2021, ISSN 2355-5920, e-ISSN 2655-1845 www.ejournal.unib.ac.id/index.php/pseudocode

hasil yaitu 75\%. Dari 44 kali identifikasi terdapat 11 kali kegagalan atau kesalahan identifikasi.

Hasil Pengujian Tekstur GLRLM dari 44 data yang berhasil diidentifikasi adalah 35 citra. Sehingga tingkat akurasi sistem untuk pencarian citra smartphone adalah sebagai berikut:

$$
\text { akurasi }=\frac{35}{44} \times 100 \%=79,5 \%
$$

Pengujian citra menggunakan citra yang diambil menggunakan smartphone mendapatkan hasil yaitu 79,5\%. Dari 44 kali identifikasi terdapat 9 kali kegagalan atau kesalahan identifikasi.

Berdasarkan hasil eksperimen yang telah dilakukan tersebut menunjukkan bahwa metode GLRLM lebih unggul dibandingkan dengan metode GLCM. Kelebihan Gray Level Run Length Matrix ini mampu membedakan citra tekstur halus dan citra tekstur kasar [10]. Sedangkan kelebihan Gray Level Co-occurrence Matrix metode ekstraksi fitur tekstur yang sangat baik untuk digunakan pada analisis citra [11].

Identifikasi kura-kura sumatera dapat menggunakan dengan menggunakan pola karapaks [12]. Pola karapaks kemudian diekstraksi fitur tekstur. Tekstur dalam citra bertujuan untuk mendapatkan estimasi ciri dengan estimasi pikselpiksel dengan derajat keabuan yang sama untuk membedakan kekasaran citra [13]. Berdasarkan hasil nilai akurasi dengan menggunakan metode GLCM dan GLRLM tersebut didapatkan bahwa metode GLRLM lebih akurat dibandingkan dengan metode GLCM dari 44 data yang digunakan dalam aplikasi identifikasi jenis kura-kura. GLCM memiliki empat ciri tekstur yaitu Energy, Contrast, Correlation, dan Homogenity [14]. Sedangkan GLRLM memiliki lima ciri tekstur, yaitu Short Run Emphasis (SRE), Long Run Emphasis (LRE), Grey Level non-Uniformity (GLU), Run Length nonUniformity (RLU), Run Percentage (RPC)
[15]. Hal ini berdampak pada tingkat akurasi GLRLM yang lebih baik daripada GLCM.

\section{KESIMPULAN}

Berdasarkan hasil penelitian dan pembahasan diketahui bahwa penelitian ini telah dapat mengidentifikasi jenis kura-kura dengan membandingkan fitur tekstur GLCM dan GLRLM dengan studi kasus citra cangkang kura-kura Bengkulu bagian atas. Identifikasi jenis Kura-kura untuk citra uji cangkang kura-kura bagian atas ini memiliki nilai akurasi $75 \%$ pada tekstur dan warna metode GLCM, dan 79,5\% pada tekstur dan warna metode GLRLM. Dari hasil nilai akurasi tersebut didapatkan bahwa penerapan metode GLRLM lebih akurat dibandingkan dengan metode GLCM dari 44 data yang digunakan dalam aplikasi identifikasi jenis kura-kura.

Saran dari penelitian ini untuk mendapatkan akurasi yang lebih tinggi dapat dilakukan dengan memperbanyak jumlah data latih agar proses pengenalan pola oleh jaringan semakin baik. Selain itu dapat dilakukan juga dengan pengembangan metode Convolutional Neural Network (CNN) sehingga tidak perlu lagi menggunakan segmentasi ekstraksi fitur tekstur.

\section{UCAPAN TERIMA KASIH}

Tim Peneliti mengucapkan terima kasih kepada Unversitas Bengkulu yang telah memberikan hibah melalui skema Penelitian Pembinaan di Fakultas Teknik Universitas Bengkulu Tahun Anggaran 2020 dengan Nomor Kontrak: 2082/UN30.13/HK/2020. 
Jurnal Pseudocode, Volume VIII Nomor 1, Februari 2021, ISSN 2355-5920, e-ISSN 2655-1845 www.ejournal.unib.ac.id/index.php/pseudocode

\section{REFERENSI}

[1] Setiadi, A. E. (2012). IDENTIFIKASI JENIS KURAKURA DI KALIMANTAN BARAT Seminar Nasional XI Pendidikan Biologi FKIP UNS Biologi, Sains, Lingkungan, dan Pembelajarannya _. 493-497.

[2] Endarwin, Wempy. (2006). Keanekaragaman jenis reptil dan biologi Cyrtodactylus cf fumosus di Taman Nasional Bukit Barisan Selatan Lampung - Bengkulu. [skripsi]

[3] Supriyadi, M. R., Endina, P. P. and Aan, E. (2018) 'Identifikasi Jenis Kura-Kura Dengan Metode Color Moment Dan Gray Level Co-Occurrence Matrix’, pp. 114.

[4] Purwandari, E. P., Hasibuan, R. U., \& Andreswari, D. (2018). Identifikasi Jenis Bambu Berdasarkan Tekstur Daun dengan Metode Gray Level Co-Occurrence Matrix dan Gray Level Run Length Matrix. Jurnal Teknologi Dan Sistem Komputer, 6(4), 146-151. https://doi.org/10.14710/jtsiskom.6.4.2018.146 -151

[5] Augustin, Irvie. (2018). Identifikasi Jenis Kelamin Berdasarkan Teraan Gigitan Berbasis Pengolahan Citra Digital Dengan Metode Gray Level Co-Occurrence Matrix (Glcm) Dan Klasifikasi Support Vector Machine (Svm). Universitas Telkom.

[6] Kusumaningtyas, S., \& Asmara, R. A. (2016) Identifikasi Kematangan Buah Tomat Berdasarkan Warna Menggunakan Metode Jaringan Syaraf Tiruan (Jst). Jurnal Informatika Polinema, 2(2), 72-75.

[7] Setiadi, Anandita Eka. (2015). Identifikasi dan deskrips karakter morfologi kura-kura air tawar dari kalimantan barat. Buletin al-ribaath, 12(1).

[8] Mohanty, A. K., Beberta, S., \& Lenka, S. K. (2011) Classifying Benign and Malignant Mass using GLCM and GLRLM based Texture Features from Mammogram.
International Journal of Engineering Research and Applications (IJERA), 1(3), 687-693.

[9] Radhakrishnan, M., \& Kuttiannan, T. (2012). Comparative Analysis of Feature Extraction Methods for the Classification of Prostate Cancer from TRUS Medical Images. International Journal of Computer Science Issues, 9(1), 171-179.

[10] Öztürk, Ş., \& Akdemir, B. (2018). Application of Feature Extraction and Classification Methods for Histopathological Image using GLCM, LBP, LBGLCM, GLRLM and SFTA. Procedia Computer Science, 132(Iccids), 40-46. https://doi.org/10.1016/j.procs.2018.05.057

[11] Kusanti, J., Penyakit, K., Padi, D., \& Haris, A. (2018). Klasifikasi Penyakit Daun Padi Berdasarkan Hasil Ekstraksi Fitur GLCM Interval 4 Sudut. Jurnal Informatika: Jurnal Pengembangan IT (JPIT), 03(01), 16.

[12] Suhartoyo, Hery., Anggraini, N., dan Listiono, Arsela Eko. (2017). Modul Pendidikan Konservasi Kura- Kura Air Tawar Sumatera Untuk Mahasiswa Sains. Bengkulu: Unit Penerbit FKIP UNIB.

[13] Purwandari, E. P. (2018). Teori dan Aplikasi Pengolahan CItra Digital. Bengkulu: Penerbit UNIB Press

[14] Honeycutt, Chris Ebey. (2008). Image analysis techniques and gray level cooccurrence matrices (GLCM) for calculating bioturbation indices and characterizing biogenic sedimentary structures, Computers and Geosciences, Vol 34, hal 1461-1472.

[15] Singh, K. S. H. R. (2016). A Comparison of Gray-Level Run Length Matrix and Gray-Level Co-Occurrence Matrix Towards Cereal Grain Classification. International Journal of Computer Engineering \& Technology,73590(7),9-17. 